\title{
New Fluorescence Sensor for Online Monitoring of Copper(II) Ion in Food Supplements
}

\author{
Anuwut Petdum ${ }^{1}$, Jitnapa Sirirak ${ }^{1}$, Nantanit Wanichacheva ${ }^{1}$ and Sumonmarn Chaneam ${ }^{1,2 *}$ \\ ${ }^{1}$ Department of Chemistry, Faculty of Science, Silpakorn University, \\ Nakhon Pathom, 73000, Thailand \\ ${ }^{2}$ Flow Innovation-Research for Science and Technology Laboratories (FIRST Labs.) \\ *schaneam@gmail.com
}

\begin{abstract}
:
In this work, a new fluorescent sensor, M201-DPA, based on helicene derivative was synthesized and used for the determination of $\mathrm{Cu}^{2+}$. M201-DPA revealed the selective ON-OFF fluorescence quenching at $524 \mathrm{~nm}$ toward $\mathrm{Cu}^{2+}$ in buffer $\mathrm{pH} 7.0$ medium. The sensor was also employed as a reagent in flow injection analysis (FIA) system for online fluorescence detection of $\mathrm{Cu}^{2+}$. Precision of the method was $1.06 \%$ RSD with a sample throughput of 70 samples $\mathrm{h}^{-1}$. Low detection limit of $8.41 \mu \mathrm{mol} \mathrm{L}^{-1}$ was achieved. Application of our method for analysis of $\mathrm{Cu}^{2+}$ in food supplements was discussed.
\end{abstract}

Key words: Copper, Fluorescent sensor, Flow injection analysis (FIA), Food supplement

\section{Introduction}

Copper deficiency can occur in malnourished infants, people who have intestinal bypass surgery, people who get too much zinc from diet or supplements and people who fed by feeding tubes. As a result, copper $\left(\mathrm{Cu}^{2+}\right)$ supplement is required to treat copper deficiency and supply the body with well-balanced amount of copper [1]. Recently, the consumption of dietary supplements has increased. However, the amount of some ingredients in dietary supplements are sometimes different from the labeled values. Moreover, there is no official study performed to assure about their efficacy and safety. Therefore, these illicit dietary supplements can become health risks. Some methods have been reported for the analysis of $\mathrm{Cu}^{2+}$ [2] such as ICP-OES, GFAAS and FAAS. Although these methods show high sensitivity, accuracy and precision, high-cost maintenance and sophisticated operation are required. Hence, it is necessary to develop a simple and economical method for analysis of $\mathrm{Cu}^{2+}$. Spectroscopic methods, including fluorometry, are commonly employed for developed method of $\mathrm{Cu}^{2+}$ analysis because the techniques are user-friendly and highly sensitivity [3]. In this work, a new fluorescent sensor specific to $\mathrm{Cu}^{2+}$ was reported. An automatic system for $\mathrm{Cu}^{2+}$ analysis was developed based on flow injection analysis (FIA) with spectrofluorometric detection. By measuring the light emission, the selective effect of $\mathrm{Cu}^{2+}$ on the quenching of the fluorescence intensity of the synthetic sensor was observed.

\section{Experiment}

In order to prepare the highly sensitive and selective fluorescent sensor for $\mathrm{Cu}^{2+}$, [5] helicene derivative, which served as a fluorophore, was connected to di2-picolylamine (DPA), which served as the recognition portion. The sensing properties of M201-DPA were investigated by fluorescence spectroscopy in aqueous acetonitrile solution $(30 \% \mathrm{v} / \mathrm{v})$ at $\mathrm{pH} 7.0$. The proposed chemical interaction of the sensing probe and $\mathrm{Cu}^{2+}$ was shown in Fig.1.

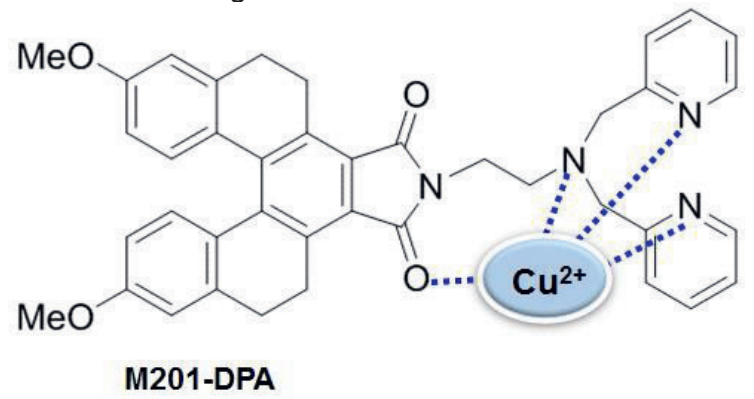

Fig.1. Chemical structure of M201-DPA: $\mathrm{Cu}^{2+}$ complex.

\section{Results and Discussion}

The sensitivity study of sensor in the presence and absence of $\mathrm{Cu}^{2+}$ was investigated via batch method and the results were shown in Fig. $2 a$. The linear calibration curve was obtained in the concentration range of $0-10 \mu \mathrm{mol} \mathrm{L}^{-1}$ of $\mathrm{Cu}^{2+}$ (Fig. 2b). 

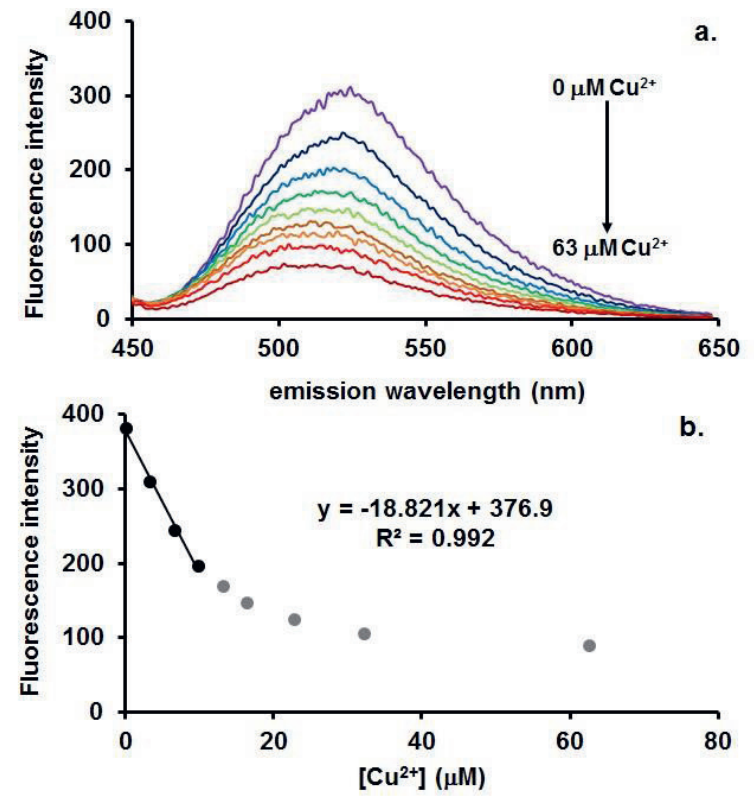

Fig.2. Emission spectrum of M201-DPA with $\mathrm{Cu}^{2+}$ at $\lambda_{e x}=389 \mathrm{~nm}$ and $\lambda_{e m}=524 \mathrm{~nm}$ in the concentration of $0,3.3,6.6,10.0,13.2,16.4$, 22.8, 32.3 and $63.0 \mu \mathrm{mol} \mathrm{L}^{-1}$.

In order to obtain rapid determination, the M201-DPA was used as a reagent for online detection of $\mathrm{Cu}^{2+}$. The FIA manifold was shown in Fig. 3. The developed system consisted of a peristaltic pump (ISM827, Ismatec, Switzerland) with tygon silicone tubing (Ismatec, Switzerland) for delivering liquid at the flow rate of $1.0 \mathrm{~mL} \mathrm{~min}{ }^{-1}$. A six-port with sample loop of 30 $\mu \mathrm{L}$ was used for sample injection (V-540, Upchurch Scientific, Germany). The FIA system was equipped with a fluorescence flow cell (Hellma Analytics,

Germany). The fluorescence signal was recorded by Perkin Elmer Luminescence spectrometer LS 50B, with excitation at $389 \mathrm{~nm}$ and emission at $524 \mathrm{~nm}$.

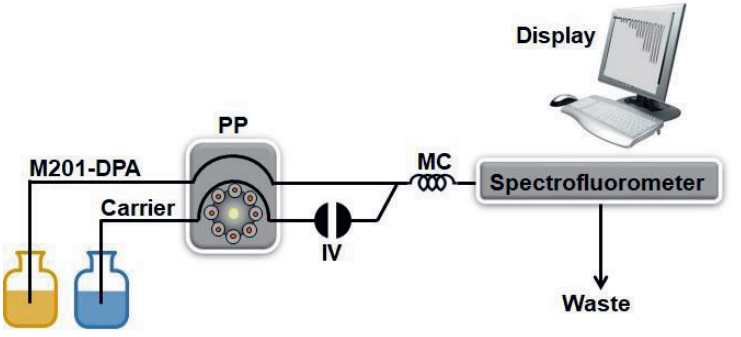

Fig. 3. FIA manifold for determination of $\mathrm{Cu}^{2+}$. $P P$, peristaltic pump $\left(1.0 \mathrm{~mL} \mathrm{~min} \mathrm{~m}^{-1}\right) ; \mathrm{IV}$, injection valve $(30 \mu \mathrm{L})$; $M C$, mixing coil $(1.0 \mathrm{~mm} \times 80 \mathrm{~cm})$.

The signal profile obtained from standard copper acetate solution at various concentrations was illustrated in Fig. 4. It can be seen that the fluorescence intensities of M201-DPA decreased
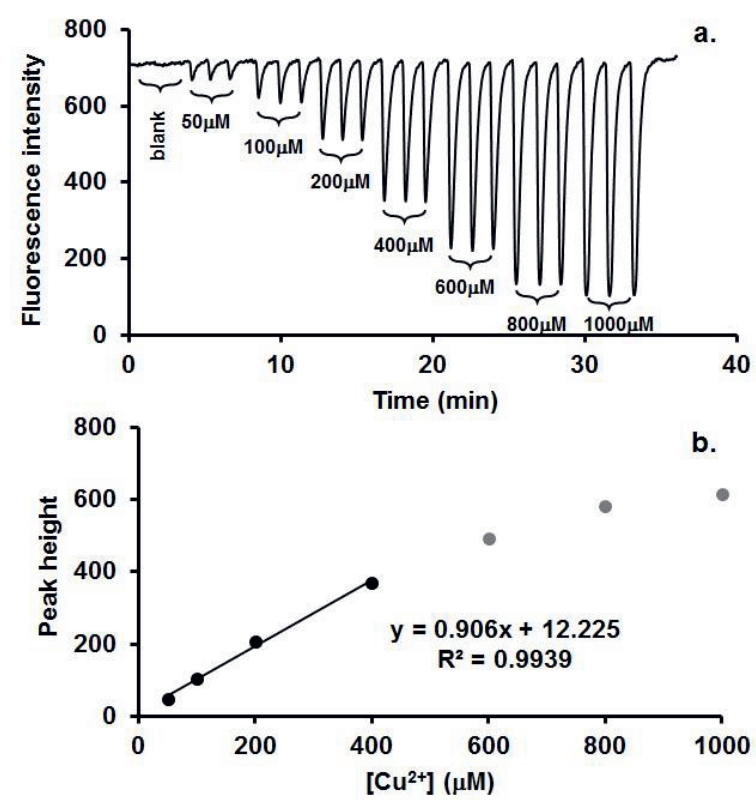

Fig. 4. Signal profile and calibration curve constructed from triplicate injections of standard $\mathrm{Cu}^{2+}$ solutions.

while $\mathrm{Cu}^{2+}$ concentrations increased. The linear curve was in the range of $50-400 \mu \mathrm{mol} \mathrm{L}{ }^{-1}$ of $\mathrm{Cu}^{2+}$. High

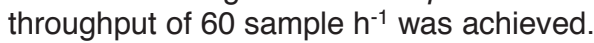

\section{Conclusion}

Here, $\mathrm{Cu}^{2+}$ was determined by the fluorescence quenching reaction with a recently synthesized selective fluoroionophore. The developed analytical system was applied to the analysis of dietary supplements. The proposed method is automatic, simple, rapid and low cost. The system of FIA coupled spectrofluorometer could be further developed as a portable device for on-site application.

\section{Acknowledgement}

The authors would like to thank financial support from Thailand Research Fund (MRG6080182).

\section{References}

[1] M. Bost, S. Houdart, M. Oberli, E. Kalonji, J. Huneau, I. Margaritis, Journal of Trace Elements in Medicine and Biology 35 (2016) 107-115.

[2] J. Marrero, R. J. Rebagliati, E. Leiva, A. Londonio, P. Smichowski, Microchemical Journal 108 (2013) 81-86.

[3] Y. Tachapermpon, S. Chaneam, A. Charoenpanich, J. Sirirak, N. Wanichacheva, Sensors and Actuators B 241 (2017) 868-878. 